\title{
A Conversation With the ABFP Executive Director
}

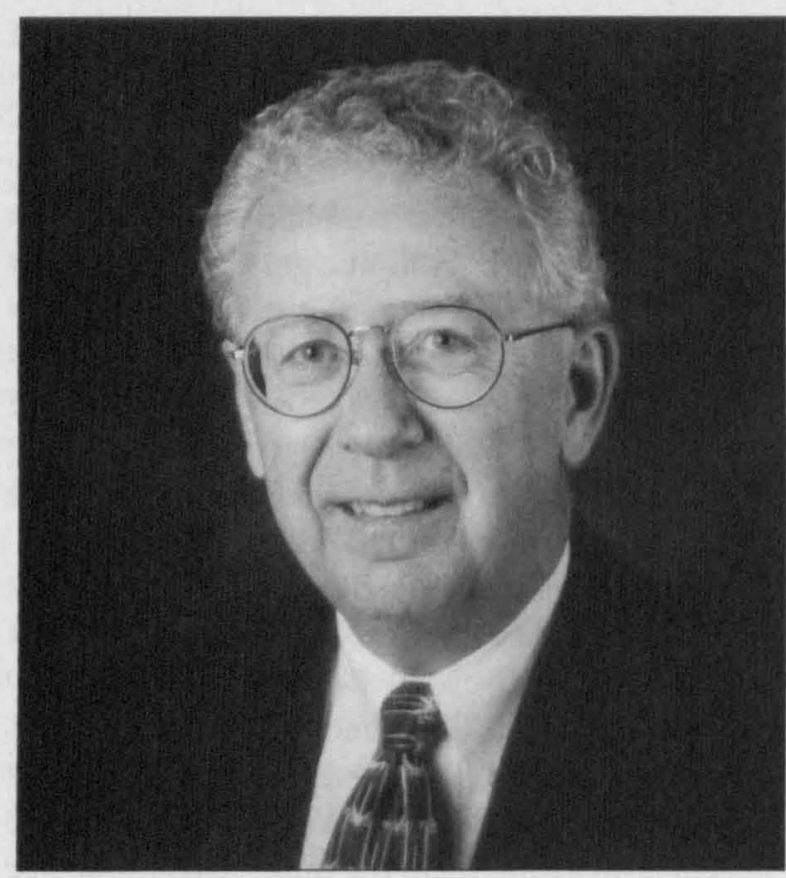

Robert Avant, MD, newly elected Executive Director of the ABFP

The American Board of Family Practice (ABFP), headquartered in Lexington, Kentucky, is the organization that certifies and recertifies family physicians. With more than 51,000 current diplomates, family practice is the second largest medical specialty in the United States. Nicholas J. Pisacano, MD, who pioneered physician recertification, founded the ABFP in 1969.

The ABFP is overseen by a board of directors, comprised of 15 board-certified physician members whose practice experience ranges from private practice to academia.

The ABFP's professional staff is guided by Robert Avant, MD, Executive Director. He also serves as president of the Nicholas J. Pisacano, MD, Memorial Foundation, Inc (NJPMF). Dr. Avant served as deputy director of the ABFP from 1990 to 1997.

Paul R. Young, MD, serves as senior executive of the ABFP. He served as executive director of the ABFP and president of the NJPMF from January 1990 until December 1997.

The following is a conversation with Dr. Avant and will appear as a regular feature in The fournal.
Who makes up the Board of Directors, and what are their responsibilities?

The Board of Directors of ABFP consists of 15 members selected by the Board. There are 10 family physicians - 5 nominated through the American Academy of Family Physicians and 5 nominated by other organizations or by the Board itself. In addition, there are representatives from five other specialties including internal medicine, surgery, pediatrics, obstetrics, and psychiatry. Each Board member serves for 5 years. The Board is responsible for making policy for the American Board of Family Practice, which includes quality standards for admission to the examinations, giving final approval of all questions on the examination, and determining the pass-fail cut-off score for the examination. All of the members of the Board of Directors are physicians and must be certified.

\section{Why must family physicians take the recertifi- cation examination every 7 years?}

The American Board of Family Practice was the first board to have mandatory recertification when it was founded in 1969. It was the expressed feeling of the Board of Directors that all certified family physicians should be required to keep their cognitive knowledge and skills up to date and that knowledge and skill levels would be measured by an office record review and a cognitive examination every 7 years. The American Board of Family Practice was a leader in mandatory recertification, and we are pleased that in 1998 all of the 24 boards under the umbrella of the American Board of Medical Specialties either have recertification processes in place or have announced their plans to develop them.

\section{Who writes and chooses the questions for the examination?}

All of the questions on the certification and recertification examinations are written by practicing board-certified family physicians. A group of approximately 50 item-writers each provide the Board with 20 questions and answers per year. All are keyed to standard references and are reviewed by the editorial staff for completeness. The ques- 
tions are selected to follow a blueprint for the examination and reviewed by examination committees, again made up of board-certified practicing family physicians. After the examination questions have been chosen and the final examination template produced, a committee made up of the current ABFP Board of Directors reviews every question for content and relevance before it is placed on the examination. After the examination is given, all questions are rated according to performance. Questions that were noted not to perform well are reviewed by the senior staff of the ABFP to determine whether the questions should be kept in the examination before the pass-fail cutoff score is established.

\section{How many physicians sit for the examination annually?}

For the 1998 examinations, there were 3734 physicians who took the certification examination and 6387 physicians who took the recertification examinations. The number of physicians taking the examination has increased substantially, with a total increase of 48 percent in the past 10 years and an increase of 36 percent in the past 5 years.

\section{With the advent of computers, do you plan any changes in bow the examination is ad- ministered?}

During the past 4 years the American Board of Family Practice has been developing a computerbased examination that will allow candidates to work through specific case scenarios by taking a history, completing a physical examination, ordering tests, and making a treatment plan. The patients' clinical profiles will evolve with time so that the physician's actions can be monitored. Sometime within the next few years the recertification examination will include the opportunity to work through case scenarios on the computer, with the plan that someday in the future the entire examination process will be administered via computer. A computer-based examination will provide the opportunity for candidates to take the examination in ways that would not require all examinees to be tested on the same day in the 20 to 25 cities, as is currently done.

Thus it is our hope that in a few years we will have a cutting-edge system of recertification that will allow more flexibility in test administration, location, and timing.

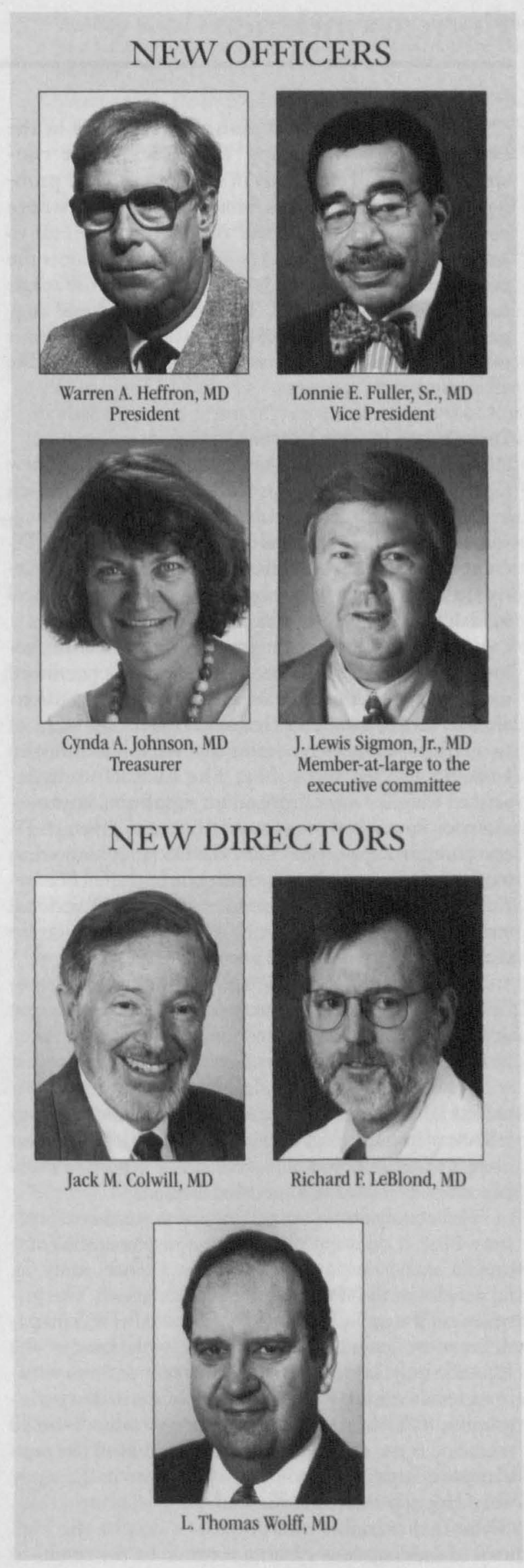

